\title{
Lockdown Policy Dilemma: COVID-19 Pandemic versus Economy and Mental Health
}

\author{
Hasan Ahamed ${ }^{1, \oplus}$, Md Tamzid Islam ${ }^{3, \oplus}$, Kazi Tanvir

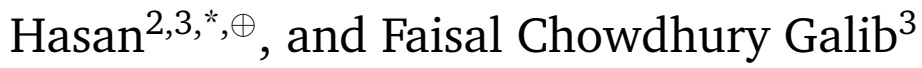 \\ ${ }^{1}$ Centre on Integrated Rural Development for Asia and the Pacific (CIRDAP), Dhaka, Bangladesh \\ ${ }^{2}$ Department of Mathematics, Illinois State University, Normal, IL, USA 617612 \\ ${ }^{3}$ Department of Statistics, University of Dhaka, Dhaka, Bangladesh \\ *Corresponding author: khasn@ilstu.edu \\ ${ }^{\oplus}$ Authors contributed equally to the article
}

Received: August 5, 2020; revised: August 22, 2020; accepted: August 24, 2020.

\begin{abstract}
Lockdown is considered to be the best of policies around the world to fight the deadly virus of COVID-19 which decimated hundreds of people in the last six months. However, this is not a cost-free measure. Billions of dollars worth of economic activities halted hinging upon these measures imposed by the governments of the countries. For instance, IMF predicted that the GDP growth will decline by 4.9 percent in 2020. Global trade is also expected to plummet by 27 percent in the second quarter of the year. In addition, paucity of recreational activities severely affects the mental health of the people. While imposing lockdown, both the cost and benefit should be analyzed to understand the real benefit of these measures on human life. This study critically examines the impact of the lockdown measures on mental health, and the economy of Bangladesh along with the efficacy of the measures on containing the virus. We found that the negative impact on the economy and mental health surpasses the positive impact of curbing the pandemic. It also compares the efficacy of the measures in different countries to find out the pattern that resembles with Bangladesh. From all the data, we conclude that the cost of lockdown measures in the country is greater than the benefit it brings to Bangladesh.
\end{abstract}

Keywords: COVID-19, Pandemic, Mental Health, Economy, Lockdown 


\section{Introduction}

In 2019, Bangladesh was one of the most burgeoning countries in the world heading towards the ambitious vision of becoming a developed nation by 2041. The achievements in the last decade cemented the position of the country much robustly that it turned its 'bottomless basket' tag into a 'development miracle'. However, the unprecedented event of coronavirus threatens to throw the country out of this swift track.

Coronavirus, while killing hundreds of people around the world, does not stop but also stymied billions of dollars worth of economic activities (IMF, 2020b). People have been forced to choose from economic hardship and health-risk. While it may not be a challenging decision for a developed country, for a developing nation, it is tremendously difficult to choose between a rock and a hard place. Not to mention that the economic stalemate may cause to drag people down beneath the vicious cycle of the poverty line. In the worst case, it may cause a famine resulting in the death of a legion of people especially those who are living under the dire poverty line. At the same time, the lockdown has several other pivotal impacts especially on mental health and daily life (Rossi et al., 2020). Several countries have reported a high surge in divorce rate and familial skirmish during the lock-down period suggesting an inflated deterioration of mental health (Brodeur et al., 2020).

This is clear that lockdown is necessary to fortify against physical health-risk of COVID19 (Alfano and Ercolano, 2020). Nevertheless, there are other factors which we have to look for i.e. mental health, economy, etc. Having enough heed to these factors, government all over the world has been responding by opening up the economic activities in a limited environment. However, one needs to be extremely cautious while taking the edge off the lockdown as it can exacerbate the situation if not backed by other resolute plans. Therefore, the decision to either continue or revoke the lockdown is a trade-off between physical health and the economy (and other sundry matters i.e. mental health). As opening-up the economic activities imperil human life, it should only be done if we follow other measures which can protect human health to a certain point and allow us to compensate greatly from economic activities at least to the point where no one dies out of starvation.

Having said that, it is unnecessary to mention the primacy of evidence-based evaluation of the economy, physical health, mental health, and other important factors to customize the policies. This paper intends to thoroughly assess the pros and cons of lockdown measures based on real-life data on different indicators. We hypothesize that the economic and mental health-related loss due to lockdown measures outstrip the benefits of containing the virus. Besides, lockdown measures in a developing economy is not as effective as a developed economy. The study will also try to shed some light on how to proceed with the policies and achieve the best out of them.

The outline of the study goes as follows- in section 2, we have literature review and then in section 3, we describe the data sources and the methodology used in this study. Section 4 explains the efficacy of lockdown measures from the both global and Bangladesh context. Section 5 and 6 analyzes the effect of lockdown measure on the economy and mental health respectively. Finally, in section 7, we present some concluding remarks.

\section{Literature Review}

As the outbreak of COVID-19 commenced only about 6 months ago, the researchers did not acquire a reasonable amount of data to conduct rigorous studies on the various impact 
of COVID-19. At the same time, complete lockdown is also a fairly new strategy again hindering us to conclude something about its impact on the economy or mental health. However, few studies have been conducted in different parts of the world which can shed some light on the present understanding of the impacts of lockdown.

Various studies have been conducted to grasp the impact of severe quarantine measures on the spread of Coronavirus, physical health, mental health, and the economy. Even though most of the studies found lockdown as an effective measure to curb the propagation of Coronavirus, some mixed results, though small in number, have also been found claiming that lockdown measures have a negligible impact on the spread of the virus. On the other hand, data exhibits a declining trend in mental health followed by strict lockdown as the contention in family and divorce rate surge significantly in the last quarter. IMF projection of GDP shows a precipitous decline in the world GDP in 2020. However, the developing nations are expected to hit much harder than the developed nation owing to the lockdown.

Many studies have found evidence regarding the efficacy of quarantine measures especially in flattening the curve- a cardinal factor to ensure medical facilities for all. Alfano and Ercolano (2020) found that the lockdown measures generally reduces the number of new cases till the 20th day from the day of initiation of the policy. Another study found that the quarantine measures in Hubei province successfully reduced the relative risk of death by 7.88 percent in a 10-day lag scenario. Tobías (2020) in a study on Spain and Italy found that diagnosed cases, ICU admission, and deaths were reduced substantially in both countries after first and second lockdown measures.

Though studies are prevalently bolstering the efficacy of quarantine measures, several studies have also found negligible alteration of the situation owing to quarantine measures. For example, (Meunier, 2020) assessed the impacts of full lockdown in the context of Italy, France, Spain, and the UK and concluded that there is no discontinuity in the trend of growth rate, doubling time, and reproduction numbers in Western Europe.

While studies exhibit mixed results in terms of preventing the outbreak of COVID-19, researchers coincide with a negative impact on the issues of both economy and mental health. The IMF projected a drop in real GDP growth to -3 percent in 2020 from 2.9 of 2019. Even emerging and developing economies are expected to grow at a negative rate which may send them back the square one. Unemployment especially in the informal sectors is expected to surge by a large margin. For example, a record 14.7 percent unemployment rate has been registered in the USA just after two months of social distancing measures (Robert 2020). Stock markets have plummeted precipitously in almost every country in the world. Scott (2020) found nearly 11 percent year-on-year contraction US real GDP as of the last quarter of 2020.

At the same time, evidence suggests a high degradation of the mental health scenario around the world caused by depression, anxiety, and boredom. Brodeur et al. (2020) analyzed Google search results and discovered a significant hike in searches related to boredom, worry, sadness, and loneliness in Europe and the USA owing to state-imposed lockdown measures. Divorce and suicide rates amplified all over the globe in recent months (Brodeur et al., 2020). Financial instability happens to be a major reason behind depression and stress. Therefore, among other reasons behind suicide, financial imbalance due to lockdown measures also plays a major role. In the developing countries, the spillover effects of economic instability on mental health caused by social distancing measures can be more severe as a substantial decline in income may drag the just above the poverty line people down 
below the poverty line. As a consequence, distress, anxiety even crimes like robbery and theft soar- evident from a study conducted by Mohler et al. (2020)

This study will rigorously assess the impacts of lockdown measures in the context of Bangladesh and will shed some light on the different traits of the country for which policy responses should differ from those of developed countries.

\section{Data Sources and Methodology}

In this study, we use secondary data sources to portray the infection rates with respect to lockdown policies along with economic phenomena and mental health conditions. The daily infection rate is obtained from Johns Hopkins University open data source Dong et al. (2020). The information related to lockdown measures taken by the governments is obtained from several trusted news portals.

We also computed the growth factor of the 'daily number of new cases' from the data to understand the growth path of the pandemic using the following formula (Worldometers, 2020).

$$
\text { GrowthFactor }=\frac{\text { every day's new cases }}{\text { new cases on the previous day }}
$$

The idea here is to see if the number of new cases increases compared to the number of new cases in the previous day. To analyze the daily new cases situation, we use scatterplot of the 'daily number of new cases' and growth factor with respect to the number of days since the first case occurred in the country. We consider a horizontal line through one as our baseline to observe the increasing or decreasing characteristics of the number of new cases per day compared to the previous day. A growth factor greater than one indicates that the number of new cases has increased compared to the number of new cases in the previous day. On the other hand, growth factor less than one indicates the number of new cases has decreased.

To obtain a trend line through new cases and growth factor scatter plots we use a local regression method based on LOESS (locally estimated scatterplot smoothing) (Fox and Weisberg, 2018).

\section{Impact of lockdown on COVID-19 infection situation}

\subsection{Global Situation}

Beginning in December 2019, the coronavirus pandemic managed to spread across all countries around the globe in the middle of March 2020. To suppress the spread of the virus, governments around the world have imposed restrictions and blockades. By March 26, around 1.7 billion people were under some form of lockdown which increased to 3.9 billion by the first week of April (Jones and Kassam, 2020) (Sandford, 2020).

Coronavirus was first detected in Wuhan, a city of Chinese province Hubei in December 2019. As the situation exacerbates, China started to implement lockdown measures from January 23 by closing the transportation in Wuhan. Afterward, the government extended the shutdown measures in several steps (Bhatia, 2020). Later on, as the infection rate plummeted, China started to mitigate these measures from 13 March (Bradsher, 2020) by 
withdrawing permit requirements on transports following by opening up Hubei province and Wuhan city on 25 March and (Davidson, 2020) 8 April respectively (Bloomberg, 2020).

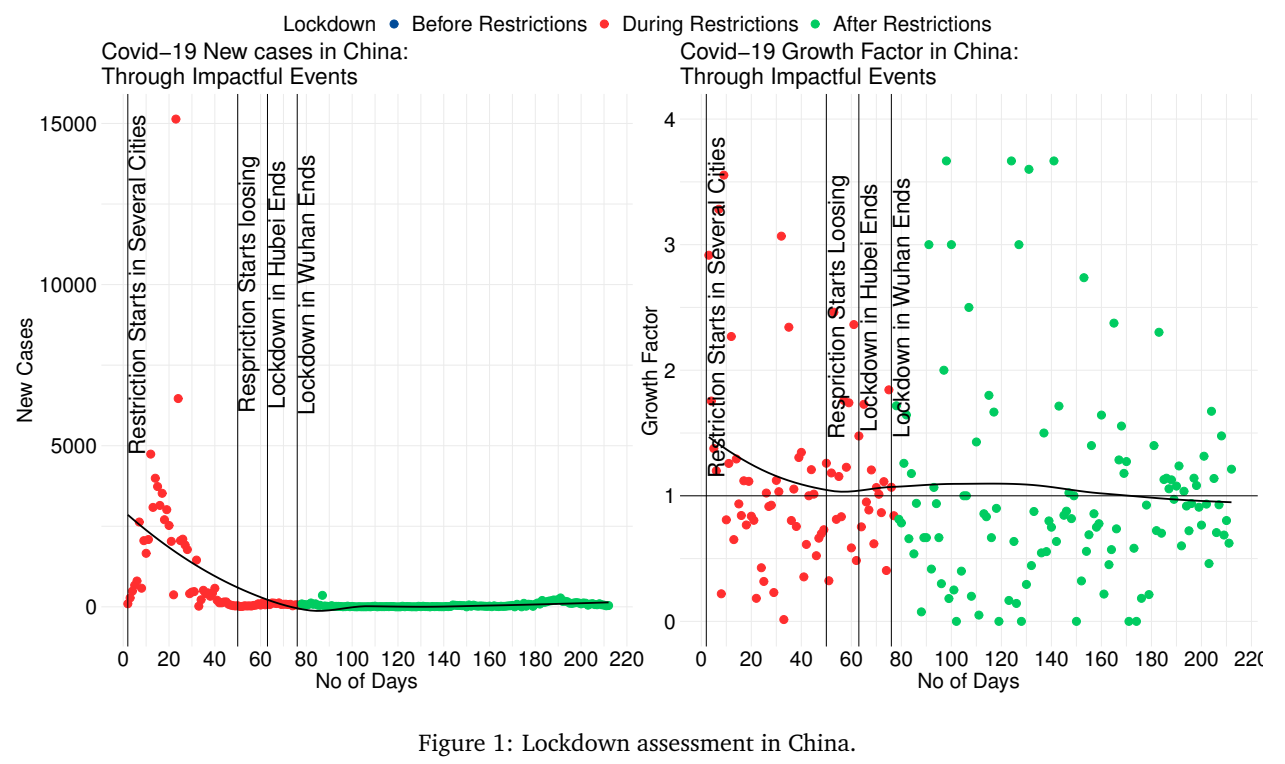

Figure 1 exhibits that the measures successfully contrived to diminish the spread as it peaked at the time of introducing these policies. After the measures were implemented, the infection rate continuously went down. The growth factor curve (Figure 1) indicates that the growth was unstable throughout the time line until the end of the lockdown measures.

To understand the global situation, our study also explores the new case and growth rates through lockdown stages of USA, Italy, Iran, Spain, Brazil, New Zealand, and India. The impact of restrictions is significantly different across these countries.

\begin{tabular}{c|c|c}
\hline Country & Start Date & End Date \\
\hline US & $17-03-2020^{[i]}$ & $26-04-2020^{[i i]}$ \\
Iran & $12-03-2020^{[i i i]}$ & $11-04-2020^{[i v]}$ \\
Italy & $09-03-2020^{[v]}$ & $18-05-2020^{[v i]}$ \\
India & $25-03-2020^{[v i i]}$ & $08-06-2020^{[v i i i]}$ \\
Spain & $14-03-2020^{[i x]}$ & $20-06-2020^{[x]}$ \\
Brazil & $18-03-2020^{[x i]}$ & $24-04-2020^{[\text {xii }]}$ \\
New Zealand & $26-03-2020^{[x i i i]}$ & $08-06-2020^{[x i v]}$ \\
\hline
\end{tabular}

Source: i) Al Jazeera (2020a), ii) Al Jazeera (2020b), iii) Garda World (2020a) , iv) Garda World (2020b), v) Economist (2020), vi) Sullivan et al. (2020), vii) Singh et al. (2020), viii) Sharma and Ghosh (2020), ix) Minder and Peltier (2020), x) Dellanna (2020), xi)

Darlington (2020), xii) Pinto (2020), xiii) Menon (2020), xiv) BBC (2020a)

Table 1: Government Lockdown/Restrictions Start and End Dates

For instance, in Italy (Figure 7), Spain (Figure 8), and New Zealand (Figure 9), the restrictions seemed to play a vital role as the infection rate decreased after the restrictions. The situation of infection rate remained low even after social distancing measures were re- 
scinded. The growth factor also indicates that at the early stages, the number of new cases was rising much rapidly day by day. During the restriction stage, as days passed, the average growth factor curve starts to come downwards near the baseline. The trend of growth factor indicates that the measures taken by the governments are playing a vital role to decrease the infection rate. However, after about two months of the restriction withdrawal, the situation in Spain is getting worse again as the number of new cases is increasing rapidly day by day. On the other hand, though the USA (Figure 10) and Iran (Figure 11) also exhibit the declining trend after the measures, new cases started to rise as the authority withdraw the measures. The growth factors remain almost the same (concentrated around 1) during and after the quarantine measures in the USA and Iran. Brazil (Figure 12) and India (Figure 13) encountered a different scenario as even after 4 months from the first confirmed case, the new cases keep going up. The authority, not being able to put up with the economic hardships, had to ease restrictions after 2-3 months. However, opening up seems to have no significant impact on the growth factor.

\subsection{Bangladesh Situation}

Bangladesh recorded the first case of COVID-19 on 8 March 2020. The government started to take some actions right after the first case. From March 25, the government declared general holidays to slow down the spread of COVID-19 (The Daily Star, 2020a). Along with the holiday declaration from the beginning of April, the government implemented several restrictions regarding industries, transportations to maintain social distances. Nonetheless, throughout April, the number of cases raised in a certain manner and growth factor was changing rapidly. In addition to this pandemic situation, several economic, social, and mental health-related crises started to emerge. For example, the price of the daily commodities increased, people fell into a severe financial shortfall due to loss of jobs and income. These caused to increase in mental stress among the people of the countries (Shammi et al., 2020). At the same time, implementing lockdown in the country turned out to be an extremely difficult job as some of the events catalyzes to hinder the implementation. For instance, the garment's owner declared to open the factories, and workers from all around the country started to come to their working place using various transportation (Dhaka Tribune, 2020a)(Dhaka Tribune, 2020b). Then on May 8, the government decided to open all the religious institutions and on May 10 most of the markets started to operate in full swing (The Daily Star, 2020b). Shopping malls were full of people defying all sorts of social distancing measures to shop for the upcoming festival of Eid-ul-Fitr.

Moreover, a large number of people, without any social distancing protocol, traveled to their respective villages from the town to celebrate Eid and then returned after a few days (Dhaka Tribune, 2020d). The economic, social, and environmental structures in Bangladesh along with these events explicates that it is incredibly difficult to implement the restriction measures like social distancing and quarantine measures. It was feared that these events will boost the growth factor of new cases each day. However, it was surprising that the growth factor did not show any significant change throughout the timeline. The number of new cases increased every day in a similar pattern. On May 30, after 67 days of restrictions, the government decided to end the general holidays (Dhaka Tribune, 2020c). Offices and all industries started to operate ensuring health protections reportedly. But in reality, the protection was not maintained appropriately by the community. Despite this fact, there was no rapid change in growth factor. It is concentrated near 1 even after a large number of 


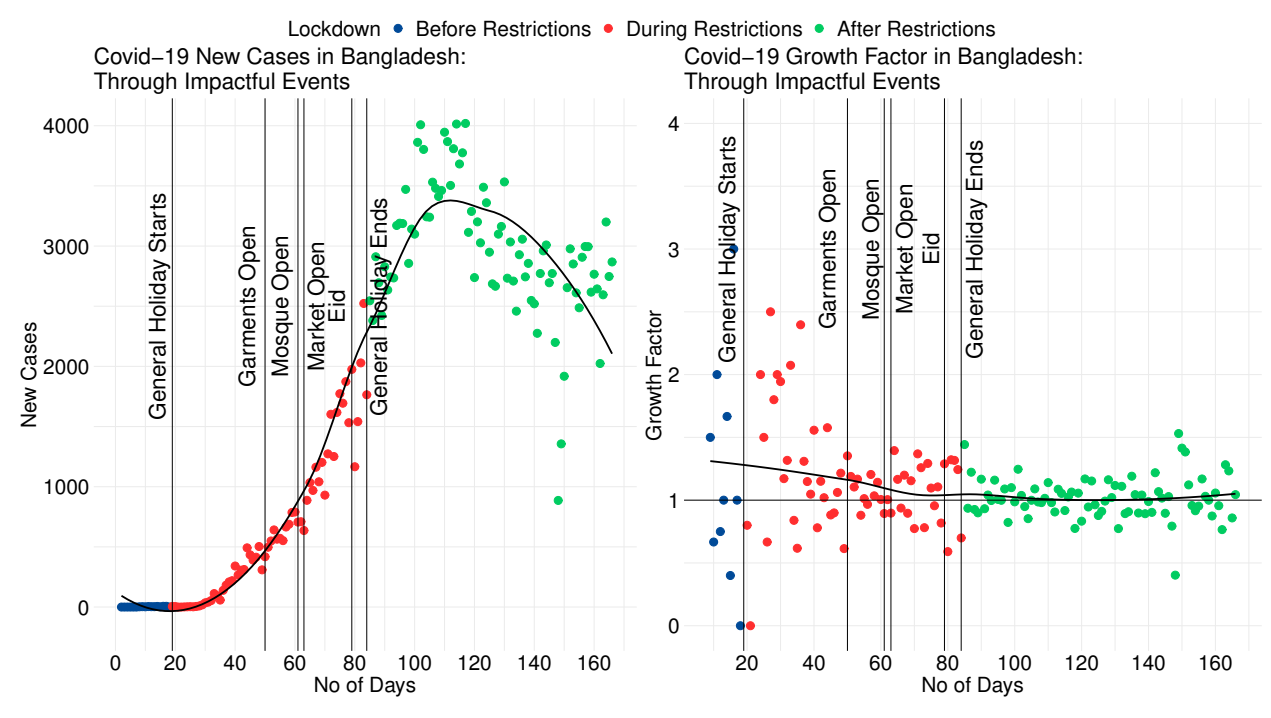

Figure 2: Lockdown assessment in Bangladesh.

people are almost back to normal life. The trend of infection rate seems independent of government policies largely owing to the fact that the society declined to comply with the rules and measures.

Contrary to most of the countries, lockdown measures in Bangladesh could not pull out the intended outcome of containing the virus as the data exhibits an upward trend in new cases per day. Restriction policies could not bring out the expected outcome due to the socio-economic and environmental situation in the country. Our study shows, for countries like Bangladesh and India, where a large number of people live behind the poverty line, restrictions do not play any vital role to improve the pandemic situation. However, the restriction policies, have some indirect effects on the various aspects of our life, especially, on the economy and mental health.

\section{Impact of Lockdown on the Economy}

\subsection{Global Situation}

Governments all over the world embraced lockdown or social distancing measures to curb the spread of COVID-19. Financial markets, corporate offices, businesses, and all other kinds of economic activities were ceased to hinder the spread of this lethal virus. As a result, economic indicators all over the world collapsed significantly intimating an imminent economic crisis equal to or even greater than the Great Depression of 1933. The June update of World Economic Outlook (IMF, 2020b) projected a -4.9 percent growth in world GDP whereas pre-COVID-19 report, the January 2020 version, projected a 3.3 percent growth in 2020. Even the recovery in 2021 is expected to be more gradual compared to the findings of the first quarter of this year.

At the same time, severe disruption in the supply chain and demand shock forced firms and businesses to curtail their production. In some cases, these commotions lead to the 
closure of the company or business. As a consequence, the unemployment rate increased substantially. For the advanced economies, the rate has been estimated at around 8.3 percent and is expected to surge especially in the highly infected areas (IMF, 2020b).

Global trade has also plummeted precipitously all over the world owing to demand shock and transport inadequacy engendered from social distancing measures. Global merchandise trades dropped 3 percent in the first quarter of 2020 and are expected to fall by 27 percent in the second quarter (World Investment Report, 2020). This fall is reducing the demand for the commodities further and catalyzing to drop in the prices of commodities significantly making the commodity markets uncertain and unstable (World Development Report, 2020)

The Great Lockdown imposes numerous threats to the economy of the world and forcing the economy to operate below 100 percent. Even though everyone may have to incur some losses, low-income people have to suffer most of the heat. Ceteris paribus, a 5 percent contraction in the per capita incomes of the world may push 124 million more people below the poverty line (Sumner et al., 2020). In a developing country, with millions of challenges, like Bangladesh, the hit is far sharper than those of the developed nations.

\subsection{Bangladesh Situation}

Up until the pandemic, Bangladesh has been burgeoning at an average rate of 7 percent in the last decade. This densely populated country is projected to grow at a rate of 2 percent, 6 percentage points lower than that of 2019 (IMF, 2020a). Poor health infrastructures, high population density, and lack of awareness among people served to propagate the virus despite strict quarantine measures. Two cardinal pillars of foreign exchange income, RMG export, and remittance, shrunk by a large margin. The triple blow dampens the once robust economy of Bangladesh dramatically in recent months following by the lockdown measures.

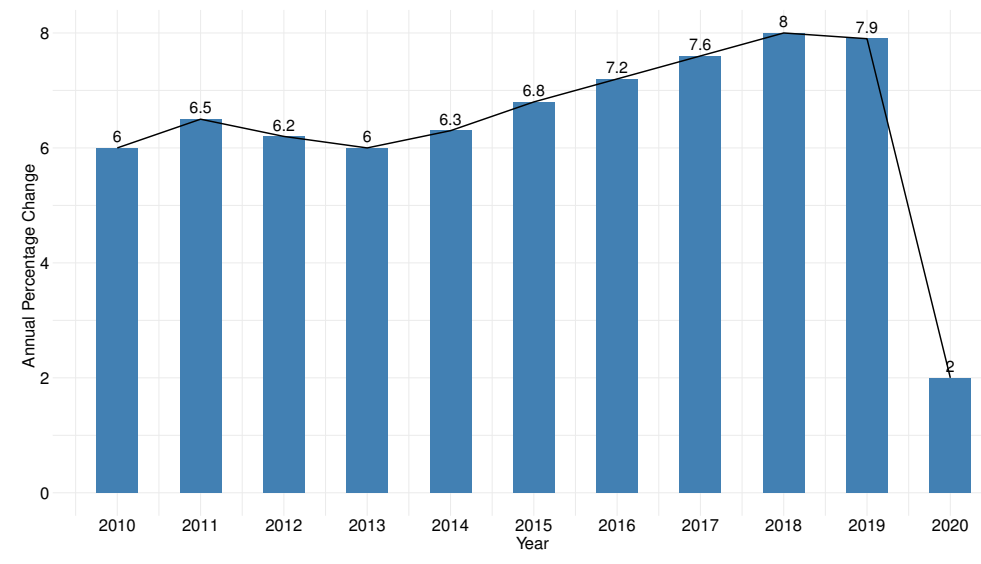

Source: COVID-19 in Bangladesh: A Visual Guide to the Economic Impact (2020) Figure 3: Real GDP Growth in Bangladesh

Sluggish economic activities imperiled millions of people from losing their jobs in industries like RMG, transportation, dairy, poultry, and many more. Workers in the informal sectors are much more susceptible to lose their jobs than the formal or corporate sectors. 50 million people in different informal sectors may lose their jobs due to the lockdown 
measures. Agriculture dependent rural economy also faces hardship as the price of their commodities plummeted swiftly because of the significant downturn in commodity demand. Prices of eggs and milk dropped 45 percent and 35 percent respectively whereas the transportation cost rises by 30 percent. Major disruptions in supply chain and inadequate labors catalyze to stymie poultry, livestock, and crop production.

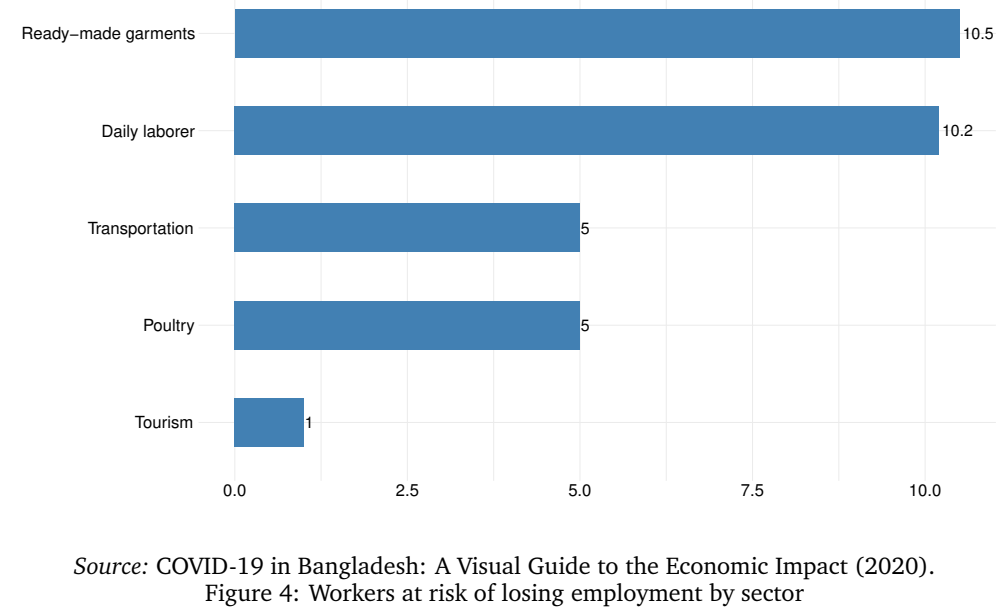

The remittance, another prime source of foreign exchange declined sharply in April 2020. In addition to global lockdown measures, a fall in oil price played a major role to deduct the amount of remittance as most of it usually comes from oil-exporting countries of the Middle East. A 353 million dollar decline from April 2019 was recorded in April 2020 (The Financial Express, 2020). The month to month remittance also fell 16 percent in April. Taking into account the surge in the unemployment rate and travel restrictions all over the world, this fall in remittance may continue for several months or longer. As most of the remittance earner belong to poor or middle-class families, inequality is expected to increase.

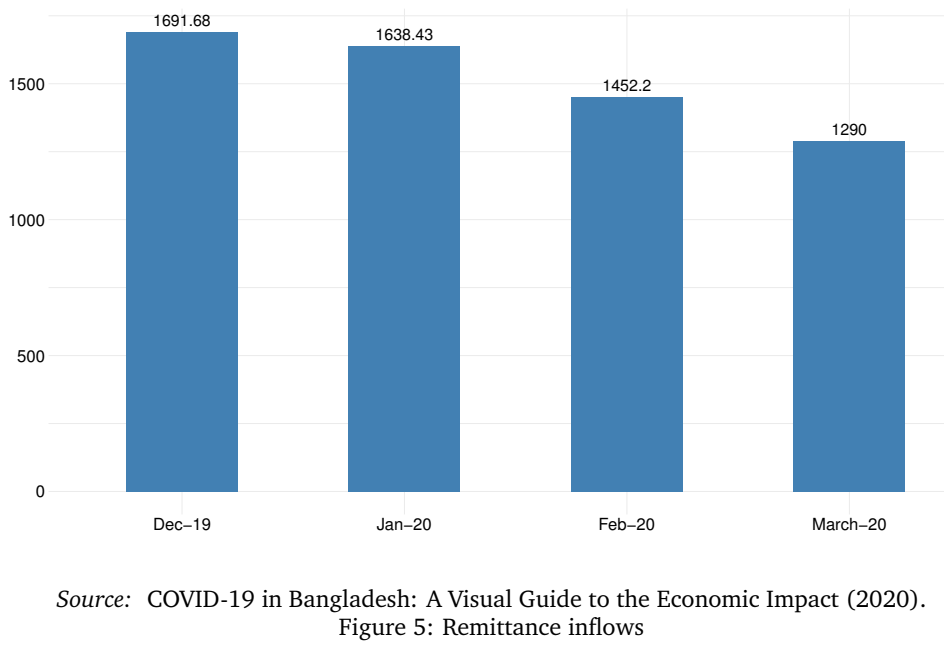

J Biomed Analytics, Vol. 3 No. 2 (2020), pp. 37-58 
The pandemic has forced to lay off many workers without zero or little compensation. Uncertainty regarding their remigration trending upward as the global economy has not been showing any sign of recovery from the shock caused by the pandemic. According to the government of the country, at least 200,000 migrant workers returned home before the closure of borders. In addition to that, government officials expect a large number of workers will be repatriated after the reopening of international flights (Sorkar, 2020). Rural to urban migration mainly for financial reason is another common scenario in the country. However, many rural migrants have also lost their jobs in this crisis engendered by the pandemic. As a result, around 15,000 families had to leave Dhaka city since the imposition of the lockdown measures (Bhuiyan, 2020). Both these foreign and urban returned people along with their families will have to endure economic hardship as job opportunities in the rural areas are scanty. In some cases, this hardship can lead to significant insecurity in terms of food consumption pushing them vulnerable to starvation. Subsequently, it can affect the mental health of the returnees severely.

Another vital source of foreign exchange of the country, RMG export encountered massive cancellation of orders as the pandemic broke out in the exporting countries especially in the USA and EU. While in April 2019, export earnings from the apparel sector were 2.53 billion US dollars, the earnings declined 85 percent amounting to only 374.67 million in April 2020. In May 2020, it continues to decline at a lower rate of 62 percent whereas the lowest reduction was only 14 percent in the last 5 years before the COVID-19 attack. A large number of garments factories were forced to close production leaving thousands of people unemployed. Since a larger share of employment in this sector is occupied by the poor women of the country, the unemployment among the vulnerable women may rise significantly.
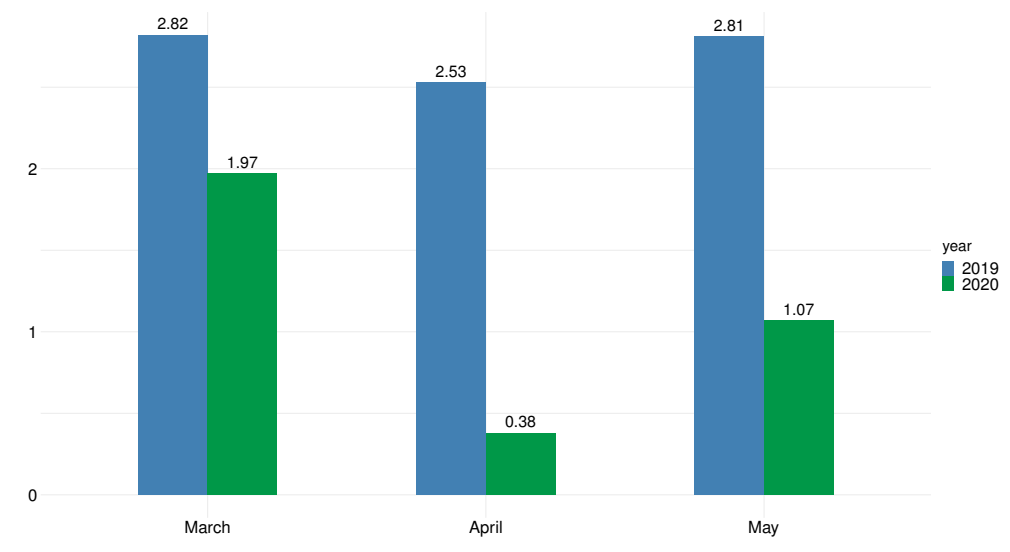

Source: COVID-19 in Bangladesh: A Visual Guide to the Economic Impact (2020). Figure 6: RMG decline due to COVID-19

Tourism, another major contributor to the foreign exchange of the country has collapsed due to the social distancing measures. Unlike others, the tourism sector is expected to continue collapsing as people are not willing to leave the house even though the lockdown measures have been retracted by the governments. Besides, WHO promulgated that the crisis of COVID-19 is highly unlikely to end soon. This announcement has also been playing a major role in keeping people inside their homes. As a result, this sector is expected to lose 
712 million dollars only in 2020. This also endangers the livelihood of 40 million people directly or indirectly related to the industry.

The stock market of the economy was passing a tough time even prior to the crisis of COVID-19. Amidst the pandemic, scared investors went for massive sell-offs plunging the DSEX, one of the prominent index of Dhaka Stock Exchange, by 19.07 percent in January to March quarter which is unprecedented in the history of DSE. Private credit growth, a cardinal factor to keep the economy growing, declined to 9.1 from 9.83 percent right after the COVID-19 hit the world. The infrastructure development projects and mega projects like Padma Bridge and Metrorail halted amid lockdown measures. Even though the central bank has a fair amount of foreign reserves, the contraction in three major pillars of foreign currency can reduce the reserve substantially. In a nutshell, every single indicator of the economy started to exhibit negative signs following the governments' quarantine measures.

\section{Impact of Lockdown on Mental Health}

\subsection{Global Situation}

Mental health is the level of psychological well-being or an absence of mental disease. It is the state of somebody who is functioning at a satisfactory level of emotional and behavioral adjustment (Infogalactic, 2020). From the perspectives of positive psychology or of comprehensive quality, the psychological state may incorporate a person's ability to enjoy life and harmonize between life activities and efforts to realize psychological resilience (Snyder et al., 2011). It influences how we think, feel, and act. It likewise decides how we handle pressure, identify with others, and settle on decisions. Mental health is significant at each phase of life, from youth and pre-adulthood through adulthood (U.S. Department of Health \& Human Services, 2020). According to the World Health Organization (WHO), the mental state includes "subjective well-being, perceived self-efficacy, autonomy, competence, inter-generational dependence, and self-actualization of one's intellectual and emotional potential, among others (World Health Report, 2001).

The outbreak of COVID-19 is heavily impacting on both physical and mental health. This outbreak is causing additional health problems such as stress, anxiety, depression, insomnia, denial, anger, and fear globally. Collective concerns influence daily behaviors, economy, prevention strategies, and decision-making from policymakers, health organizations, and medical centers, which can weaken the strategies of COVID-19 control and lead to more morbidity and mental health needs at a global level (Torales et al., 2020).

In recent months, both the number of confirmed and death cases associated with COVID19 have increased substantially. Consequently, the entire world has come to a standstill and there are enough reasons to feel sad and depressed. 'Lockdown' and 'isolation', two highly pronounced words, have caused everyone to feel countless different emotions and anxieties, loneliness, falling behind at work, stressed about friends and family, and many more. Many of us are feeling nothing but hopelessness. A mental health survey in Wuhan after the COVID-19 outbreak has already shown that isolation due to quarantine can affect our mental health (Wang et al., 2020).

With strict preventative measures by the Indian Government in the form of nationwide lockdown, the citizens are going through a range of psychological and emotional difficulties; fear of uncertainty is one of them. Evidence suggests that there is a significant difference in the level of depression, anxiety, and stress across age, gender, and levels of employment 
status. Also, depression was found to be high among the respondents of age range 15-35 years, anxiety was found to be prevalent among those belonging to 21-25 years of age, and stress was found high among individuals of 21-25 years of age (Kazmi et al., 2020). A study of COVID-19 pandemic and lockdown measures' impact on mental health among the general population in Italy shows high rates of negative mental health outcomes after three to four weeks into lockdown (Rossi et al., 2020).

While lockdowns may help to contain the spread of the virus, substantial damage to population well-being is a probable side effect of these measures. For example, limiting the extent of recreational activities deteriorates mental health further. A study, depending on

Google Trends data, tests whether the lockdowns implemented in Europe and America led to changes in the frequency of Google search related to mental health issues. Using different methods to evaluate the causal effects of lockdown, the study found a substantial increase in the search for boredom, loneliness, worry, and sadness in Europe and the US. Divorce data suggests that people's mental health may have been severely affected by the lockdown causing the divorce rate to go up (Brodeur et al., 2020).

Economic hardship engendered from lockdown is another crucial factor. More than 20 million jobs in the United States were lost in April, bringing the unemployment rate close to 15 percent. Nearly half of the Americans in the lower-income households say they've experienced job or wage losses due to the pandemic (Gray, 2020). Fear of losing jobs also has a significant impact on mental health. Psychologists argue that losing a job often equates to the grief of losing a loved one. Studies show that people, who suffered economic, housing, or job-related hardship following the Great Recession, were more vulnerable to mental health problems (BBC, 2020b).

The worldwide rapid increase of infected cases has created a tremendous level of stress among the university fraternity, inclusive of students. This stress may lead to unfavorable effects on the learning and psychological health of students (Al-Rabiaah et al., 2020) (Kafka, 2020). International students staying far from home are not only worried about their health, safety, and education but they are also concerned about the wellbeing of their family members. Students, who managed to go home, are worried about being unable to return to their respective institutions for further studies (World Development Report, 2020)(Cheng, 2020).

\subsection{Bangladesh Situation}

Bangladesh's mental health policy, strategy, and plan were approved in 2006 as a part of the policy, strategy, and strategy for surveillance and prevention of Non-Communicable Diseases (NCD) and community-based activities in mental health is the main approach of the policy. Nevertheless, there is no specific mental health authority in the country (WHO-AIMS Report, 2007). Bangladesh has a population of 160 million with only 50 clinical psychologists and 200 psychiatrists. That is 800,00 people for every single mental health specialist (Action on Disability and Development, 2020).

In Bangladesh, systematically collected data on mental disorders are scarce and this leaves the extent of the problem not so well defined. People usually are a bit oblivious about the mental health condition. In some rustic areas, the topic of mental health is still considered taboo to some extent. When people face problems with mental disorders, the researchers said, $5.7 \%$ of them think if they visit psychiatrists, they might treat as mad. At the same time, statistics exhibit that depression was soaring in the past years. Nearly $17 \%$ 
of adults in Bangladesh are suffering from mental health issues, where $16.8 \%$ are men and $17 \%$ are women, and among them, $92.3 \%$ do not seek medical attention (Rahman, 2020).

Amongst all these crises, a newly introduced demon, lockdown measures, severely limits the scope of entertainment and recreation leading people to depression and anxiety. This COVID-19 outbreak imposes psychological consequences on people to a higher extent, which needs attention from the concerned authorities to cope with this situation mentally. The perception of the occurrence may play a big role in psychological impact. Fear of infection, financial uncertainty, inadequate food supplies, absence of physical exercise, and limited or no recreational activity had a significant association with stress, anxiety, depression, and post-traumatic symptoms (Khan et al., 2020). A nationwide cross-sectional study shows that the prevalence of stress, anxiety, and depression was 59.7\%, 33.7\%, and 57.9\%, respectively. It also shows that age, gender, marital status, education, income, residence, and the presence of an elderly family member are associated with mental health outcomes (Banna et al., 2020).

Economic recession, unemployment, and poverty are strongly related to severe psychological comorbidities like suicidal behaviors. Without early interventions from the respective authority, such mental state problems will promote self-destructive behaviors among some people. There are at least eight COVID-19 suicide cases in Bangladesh (Bhuiyan et al., 2020). A recent study on mental health by Wazed et al. shows that $91.4 \%$ of the respondents were concerned about this epidemic. Amongst them, $72.6 \%$ suffered from insomnia, $61.7 \%$ were upset and angry at the situation created by the epidemic, and $83.5 \%$ of respondents expressed frustration and apprehension about the future. $68.2 \%$ of the respondents said that they are terrified of the epidemic situation and $59.4 \%$ of respondents said that life had become meaningless to them (TBS Report, 2020).

Integrating specialized health services like mental health services into Primary Health Care (PHC) is one of the most basic health care recommendations of the World Health Organization (WHO). However, any decision to incorporate mental health in the PHC has not been taken by the government of the country to date. The burden of mental health issues in Bangladesh is yet to be estimated precisely as done in the developed nations. Mental health services are concentrated around tertiary care hospitals in big cities and there is little awareness of mental health disorders at the community level. A large number of people, suffering from mental health disorders, reports to a range of traditional health care providers like Kabiraj, Totka, faith healers (Pirs and Fakirs), homeopathic practitioners, rural medical practitioners (village doctors), community health workers and retail medicine sellers as their first point of contact for health care(Arafat et al., 2018). But it is a good thing that the government and the denizens of the country start realizing the importance of mental health and start taking serious actions. More people are being cautious about mental health and reporting to the experts to resolve the issue. From the government side, the mental health policy was revised, which includes the organization of services and developing community mental health services. But it is crucial to include the mental health component in almost all health care of the country like the developed countries.

\section{Conclusion}

The lockdown measures have considered to be an important policy in containing the spread of COVID-19 all around the world. However, the indirect effect of these measures on economy and mental health is also an alarming issue. This study rigorously assessed the eco- 
nomic and mental health effects of the lockdown measures especially in Bangladesh. While this is apparent that the measures are directly related to the mental and economic downturn, the study did not find a substantial impact of these measures on the spread of COVID-19. Several factors have been catalyzing to stymie the efficacy of the lockdown on the outbreak of COVID-19. It is not easy to implement a lockdown policy due to people's lack of awareness and limited financial capacity. Moreover, the mental health of the populace of the country especially students poses a severe threat as they pass sluggish times having no recreation for a long time. Combining all of these, this study concludes that the lockdown measures in Bangladesh engender severe economic and mental health issues while not proved efficient in curbing the outbreak of the virus. Therefore, these measures should be re-evaluated by the governments and the various sector specialists to create some policies keeping in mind the situation of the economy and mental health.

At the same time, the World Health Organization (WHO) has warned the global leaders about the second wave which may be far more menacing than the first wave. In that case, another lockdown can be imposed and the situation may deteriorate rapidly due to prolonged and consistent pressure on both the economy and mental health. Finally, permanent solutions, i.e. vaccine, need to be developed and we must self-aware to survive this vicious situation.

\section{Limitations of the study}

This study has some limitations which need to be mentioned. COVID-19 is a fairly new issue and the available data to explain the impacts of this phenomenon lucidly are not sufficient. At the same time, prevalent policy lags affect economic variables widely hindering us to perceive the long-run consequences of government policies. Another limitation of this study is the data quality. This study has been developed mostly from the data supplied by the government sources. It can be argued that the data in a developing country like Bangladesh suffers from some bias. Therefore, the results achieved from the analysis in the data may subject to some bias.

\section{Acknowledgments}

We would like to thank all the people who helped and supported us in the process of writing the research paper.

\section{Declarations}

Funding: This research did not receive any specific grant from funding agencies in the public, commercial, or not-for-profit sectors.

Conflict of interest: We declare no conflict of interest.

\&RF www.jBiomedAnalytics.org 


\section{References}

Action on Disability and Development (2020). "Mental Health Bangladesh." URL https:// www.add.org.uk/mental-health-bangladesh.

Al Jazeera (2020a). "Lockdowns, closures: How is each US state handling coronavirus?" URL https://rb.gy/bk7t8b.

Al Jazeera (2020b). "More US states set to ease coronavirus lockdown measures." URL https://rb.gy/04poii.

Al-Rabiaah A, Temsah MH, Al-Eyadhy AA, Hasan GM, Al-Zamil F, Al-Subaie S, Alsohime F, Jamal A, Al-Saadi B, Somily AM (2020). "Middle East Respiratory Syndrome-Corona Virus (MERS-CoV) associated stress among medical students at a university teaching hospital in Saudi Arabia." Journal of Infection and Public Health, 13(5), 687-691. doi:10.1016/j.jiph.2020.01.005.

Alfano V, Ercolano S (2020). "The Efficacy of Lockdown Against COVID-19: A Cross-Country Panel Analysis." Appl Health Econ Health Policy, 18, 509-517. doi:10.1007/s40258-02000596-3.

Arafat SY, Roy S, Huq N (2018). "Integrating mental health into primary health care in Bangladesh: problems and prospects." Mental Health and Addiction Research, 3(2), 509517. doi:10.15761/mhar.1000158.

Banna MHA, Sayeed A, Kundu S, Christopher E, Hasan MT, Begum MR, Kormoker T, Dola STI, Hassan MM, Chowdhury S, Khan MSI (2020). "The impact of the COVID-19 pandemic on the mental health of the adult population in Bangladesh: A nationwide crosssectional study." International Journal of Environmental Health Research, 0(0), 1-12. doi:10.31234/osf.io/chw5d.

BBC (2020a). "New Zealand lifts all Covid restrictions, declaring the nation virus-free." URL https://rb.gy/y5yvki.

BBC (2020b). "Unemployment during coronavirus: The psychology of job loss." URL http: //shorturl.at/hqACG.

Bhatia G (2020). "Under China's lockdown, millions have nowhere to go." Reuters. URL https://rb.gy/eohd8t.

Bhuiyan AH (2020). "Pandemic pushes back rural migrants." The Financial Express. URL https://rb.gy/nmlwvz.

Bhuiyan AI, Sakib N, Pakpour AH, Mamun MA (2020). "COVID-19-Related Suicides in Bangladesh Due to Lockdown and Economic Factors: Case Study Evidence from Media Reports." International Journal of Mental Health and Addiction. doi:10.1007/s11469-02000307-y.

Bloomberg (2020). "China to Lift Lockdown Over Virus Epicenter Wuhan on April 8." URL https://rb.gy/3fbnbg. 
Bradsher K (2020). "Halting China's Economy Was Hard. Restarting It Is Harder." The New York Times. URL https://rb.gy/mzcryz.

Brodeur A, Clark AE, Fleche S, Powdthavee N (2020). "Assessing the impact of the coronavirus lockdown on unhappiness, loneliness, and boredom using Google Trends." arxiv.org. URL https://arxiv.org/abs/2004.12129v1.

Cheng R (2020). "Higher ed institutions aren't supporting international students." URL https://rb.gy/mcdbjh.

Darlington S (2020). "Brazil's Bolsonaro calls coronavirus measures 'hysteria'." CNN. URL https://rb.gy/oct4ub.

Davidson H (2020). "China to lift travel restrictions in Hubei after months of coronavirus lockdown." The Guardian. URL https://rb.gy/t8r37j.

Dellanna A (2020). "Coronavirus: Spain ends state of emergency. People and tourists free to move across the country." Euronews. URL https://rb.gy/9ua67i.

Dhaka Tribune (2020a). "Apparel factories to reopen in phases, zone-wise on Sunday." URL https://rb.gy/wlshxh.

Dhaka Tribune (2020b). "Bangladesh Muslims join Jummah prayers at mosques after a month." URL https://rb.gy/hvpaom.

Dhaka Tribune (2020c). "COVID-19: Bangladesh likely to end general holiday on." URL https://rb.gy/svbre1.

Dhaka Tribune (2020d). "Eid-ul-Fitr on Monday." URL https://rb.gy/ggpuqu.

Dong E, Du H, Gardner L (2020). "An interactive web-based dashboard to track COVID-19 in real time." Lancet Inf Dis. doi:10.1016/S1473-3099(20)30120-1.

Economist T (2020). "Italy, the first country in Europe to enter lockdown, starts to emerge." URL https://rb.gy/fflpjo.

Fox J, Weisberg S (2018). An Appendix to An $R$ Companion to Applied Regression. URL https://socialsciences.mcmaster.ca/jfox/Books/Companion/appendices/ Appendix-Nonparametric-Regression.pdf.

Garda World (2020a). "Iran: Natiowide lockdown implemented as over 11,300 COVID-19 cases confirmed March 13 /update 12." URL https://rb.gy/7yybin.

Garda World (2020b). "Iran: Partial relaxation of COVID-19 lockdown restrictions." URL https://rb.gy/pfic7a.

Gray D (2020). "Job Loss Anxiety Could Be a Side Effect of COVID-19. Here Are Ways to Cope." URL https://rb.gy/zjqtj2.

IMF (2020a). "Helping Bangladesh Recover from COVID-19." URL https://rb.gy/cpspx1.

IMF (2020b). "World Economic Outlook, April 2020: The Great Lockdown."

Infogalactic (2020). "Mental health." URL https://infogalactic.com/info/Mental_health.

BRF Www.jBiomedAnalytics.org 
Jones S, Kassam A (2020). "Spain defends response to coronavirus as global cases exceed 500,000." The Gurdian. URL https://rb.gy/efcsnh.

Kafka AC (2020). "Shock, Fear, and Fatalism: As Coronavirus Prompts Colleges to Close, Students Grapple With Uncertainty." URL https://www.chronicle.com/article/ Shock-FearFatalism-As/248240.

Kazmi SSH, Hasan DK, Talib S, Saxena (2020). "COVID-19 and Lockdwon: A Study on the Impact on Mental Health." SSRN. doi:doi:10.2139/ssrn.3577515. URL https://papers. ssrn.com/sol3/papers.cfm?abstract_id $=3577515$.

Khan AH, Sultanaa M, Hossain S, Hasan MT, Ahmed HU, Sikder Md T (2020). "The impact of COVID-19 pandemic on mental health \& wellbeing among home-quarantined Bangladeshi students: A cross-sectional pilot study." Journal of Affective Disorders. doi:doi:10.31234/osf.io/97s5r.

Menon P (2020). "New Zealand falls silent on day one of coronavirus lockdown." Reuters. URL https://rb.gy/sem3dv.

Meunier TA (2020). "Full lockdown policies in Western Europe countries have no evident impacts on the COVID-19 epidemic." The Lancet Psychiatry, 7(4).

Minder R, Peltier E (2020). "Spain Imposes Nationwide Lockdown to Fight Coronavirus." URL https://rb.gy/vwrwn6.

Mohler G, Bertozzi AL, Carter J, Short MB, Sledge D, Tita GE, Uchida CD, Brantingham J (2020). "Impact of social distancing during COVID-19 pandemic on crime in Los Angeles and Indianapolis." Journal of Criminal Justice, 68(4). doi:10.1016/j.jcrimjus.2020.101692.

Pinto AR (2020). "Malls Reopen as Brazil Quarantine Begins to Ease; Deaths Jump."

Rahman M (2020). "16.8\% Bangladeshi adults suffer from mental health issues." URL https://rb.gy/vvu4uas.

Rossi R, Socci V, Talevi D, Mensi S, Niolu C, Pacitti F, Marco AD, Rossi A, Siracusano A, Lorenzo GD (2020). "COVID-19 pandemic and lockdown measures impact on mental health among the general population in Italy An $\mathrm{N}=18147$ web-based survey." doi:10.1101/2020.04.09.20057802.

Sandford A (2020). "Coronavirus: Half of humanity now on lockdown as 90 countries call for confinement." Euronews with AP, AFP.

Shammi M, Bodrud-Doza M, Reza A, Islam MT, Rahman MM (2020). "COVID-19 pandemic, socioeconomic crisis and human stress in resource-limited settings: A case from Bangladesh." Heliyon, 6(5). doi:10.1016/j.heliyon.2020.e04063.

Sharma N, Ghosh D (2020). "'Unlock1": Malls, Restaurants, Places Of Worship To Reopen June 8." NDTV.

Singh KD, Goel V, Kumar H, Gettleman J (2020). "India, Day 1: World's Largest Coronavirus Lockdown Begins." The New York Times. 
Snyder CR, Shane LJ, Jennifer TP (2011). Positive psychology: The scientific and practical explorations of human strengths. Los Angeles: SAGE.

Sorkar M (2020). "COVID-19 Pandemic Profoundly Affects Bangladeshi Workers Abroad with Consequences for Origin Communities."

Sullivan H, Rawlinson K, Ames N, Walker A, Murray J (2020). "Italy begins reopening bars and cafes as rate of deaths and new infections falls again - as it happened." URL https://rb.gy/c9xrzk.

Sumner A, Hoy C, Ortiz-Juarez E (2020). "Estimates of the impact of COVID-19 on global poverty." doi:10.35188/unu-wider/2020/800-9.

TBS Report (2020). "72\% Bangladeshis suffer from insomnia due to COVID-19." URL https://shorturl.at/hnpO1.

The Daily Star (2020a). "Coronavirus outbreak: Govt orders closure of public, private offices from March 26 to April 4.” URL https://rb.gy/m8xt5e.

The Daily Star (2020b). "Shopping malls, markets to remain open from May 10." URL https://rb.gy/dvnrne.

The Financial Express (2020). "Remittance drops 25pc in April." URL https://rb.gy/fu18hs.

Tobías A (2020). "Evaluation of the lockdowns for the SARS-CoV-2 epidemic in Italy and Spain after one month follow up, Science of The Total Environment." 725. doi:10.1016/j.scitotenv.2020.138539.

Torales J, OâĂŹHiggins M, Castaldelli-Maia JM, Ventriglio A (2020). "The outbreak of COVID-19 coronavirus and its impact on global mental health." International Journal of Social Psychiatry, 66(4), 317-320. doi:10.1177/0020764020915212.

US Department of Health \& Human Services (2020). "What Is Mental Health?” URL https: //www.mentalhealth.gov/basics/what-is-mental-health.

Wang C, Pan R, Wan X, Tan Y, Xu L, McIntyre RS, Choo FN, Tran B, Ho R, Sharma VK, Ho C (2020). "A longitudinal study on the mental health of general population during the COVID-19 epidemic in China." Brain, behavior, and immunity, 87, 40-48. doi:10.1016/j.bbi.2020.04.028.

WHO-AIMS Report (2007). "WHO-AIMS Report on Mental Health System in Bangladesh."

World Development Report (2020). "World Development Report 2020: Trading for Development in the Age of Global Value Chains."

World Health Report (2001). "The world health report 2001 - Mental Health: New Understanding, New Hope."

World Investment Report (2020). United Nations Publications. URL https://rb.gy/0d3ywk. Worldometers (2020). "Coronavirus Cases: Growth Factor." URL https://rb.gy/qglbed. 


\section{Appendix}
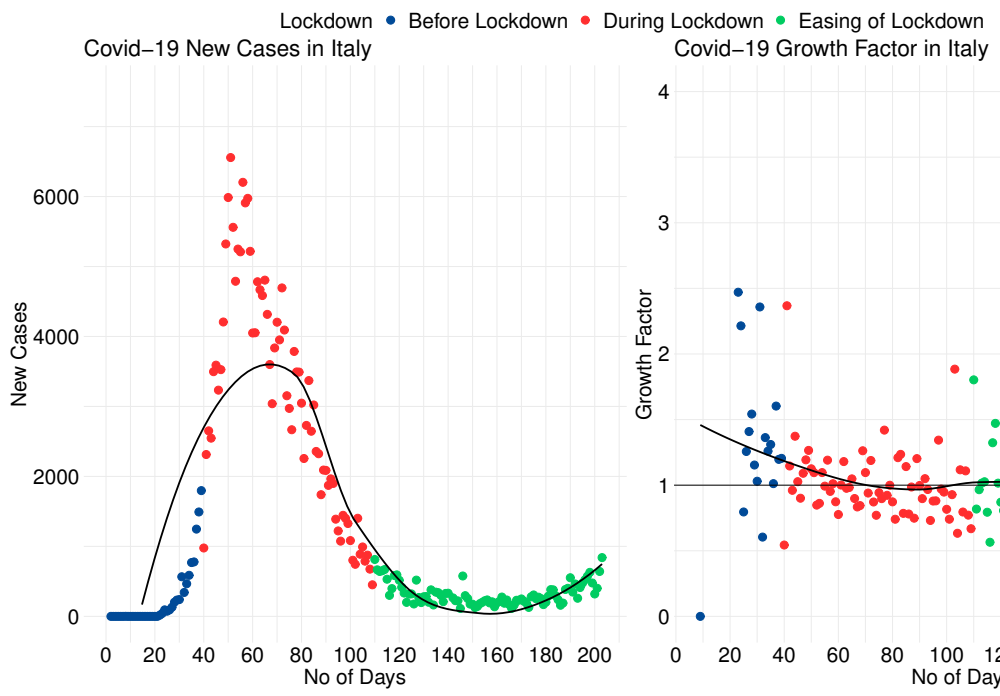

Figure 7: Lockdown assessment in Italy.

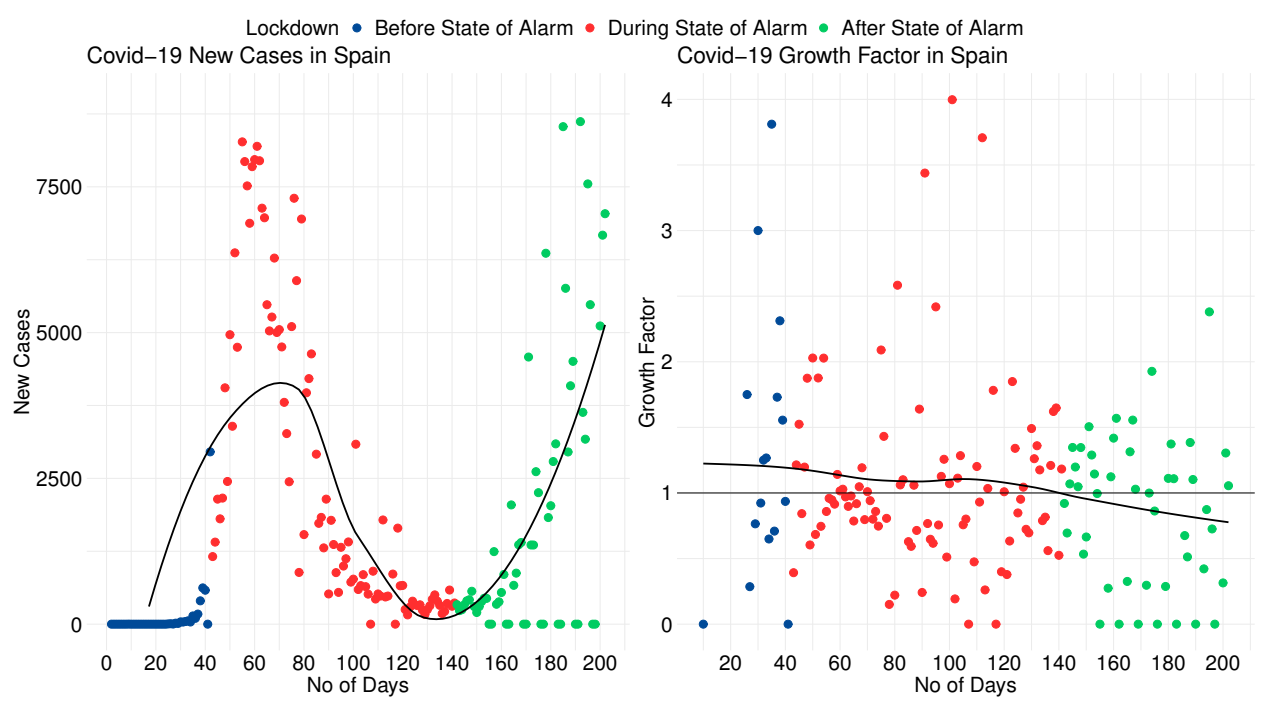

Figure 8: Lockdown assessment in Spain.

J Biomed Analytics, Vol. 3 No. 2 (2020), pp. 37-58 


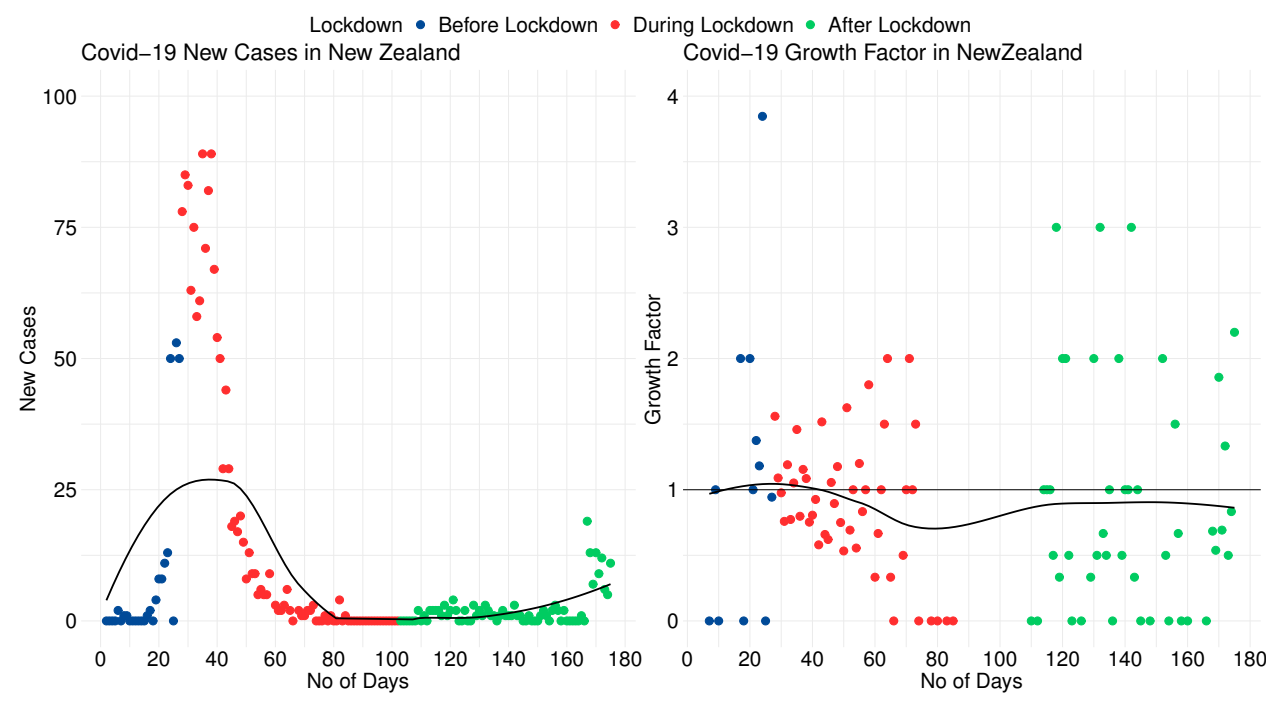

Figure 9: Lockdown assessment in New Zealand.

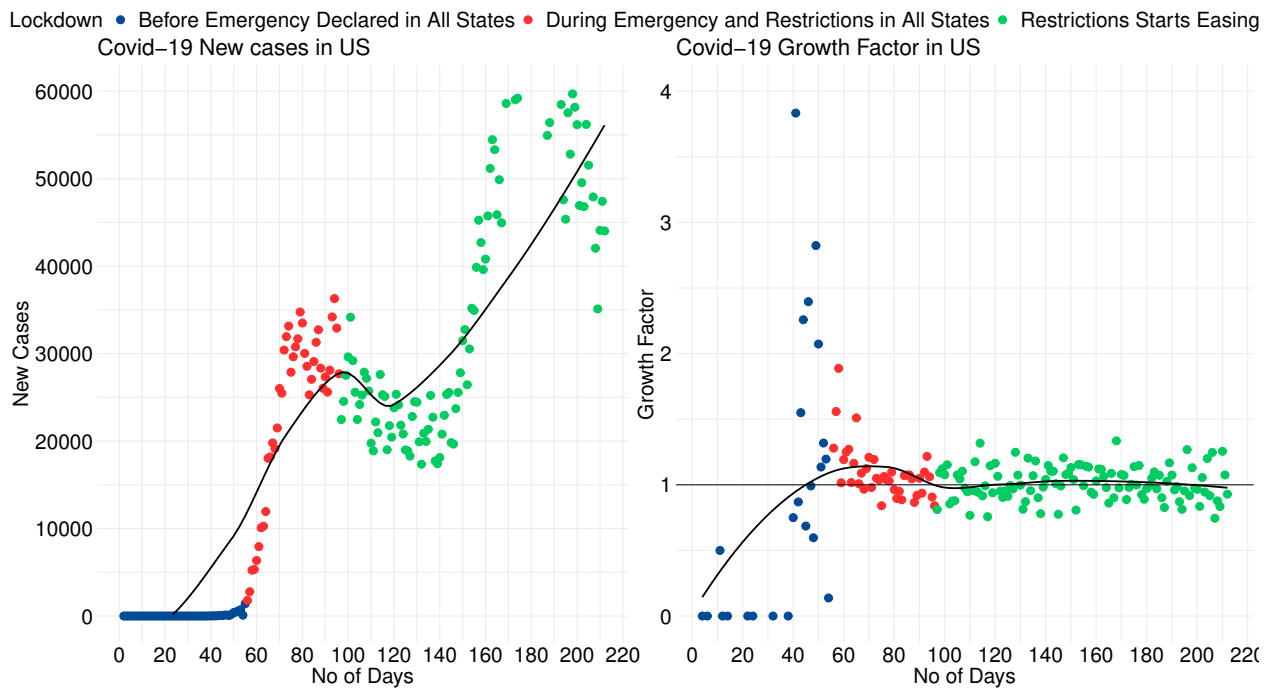

Figure 10: Lockdown assessment in USA. 


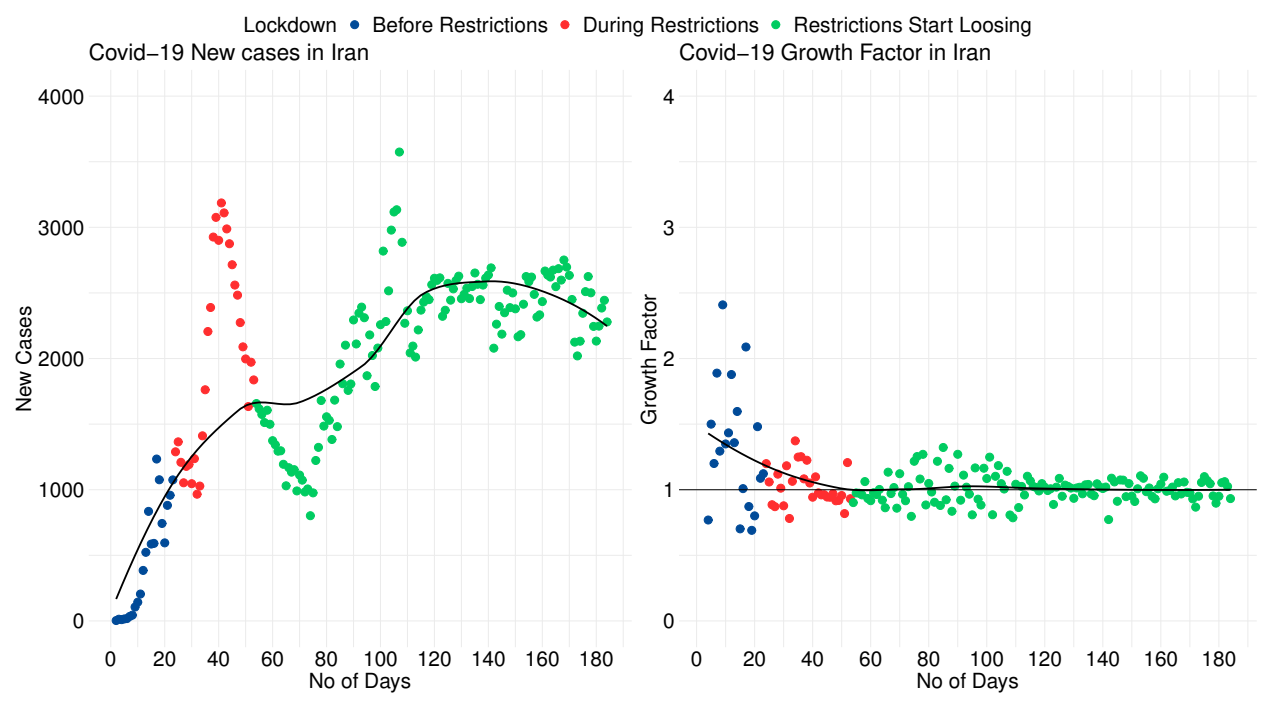

Figure 11: Lockdown assessment in Iran.

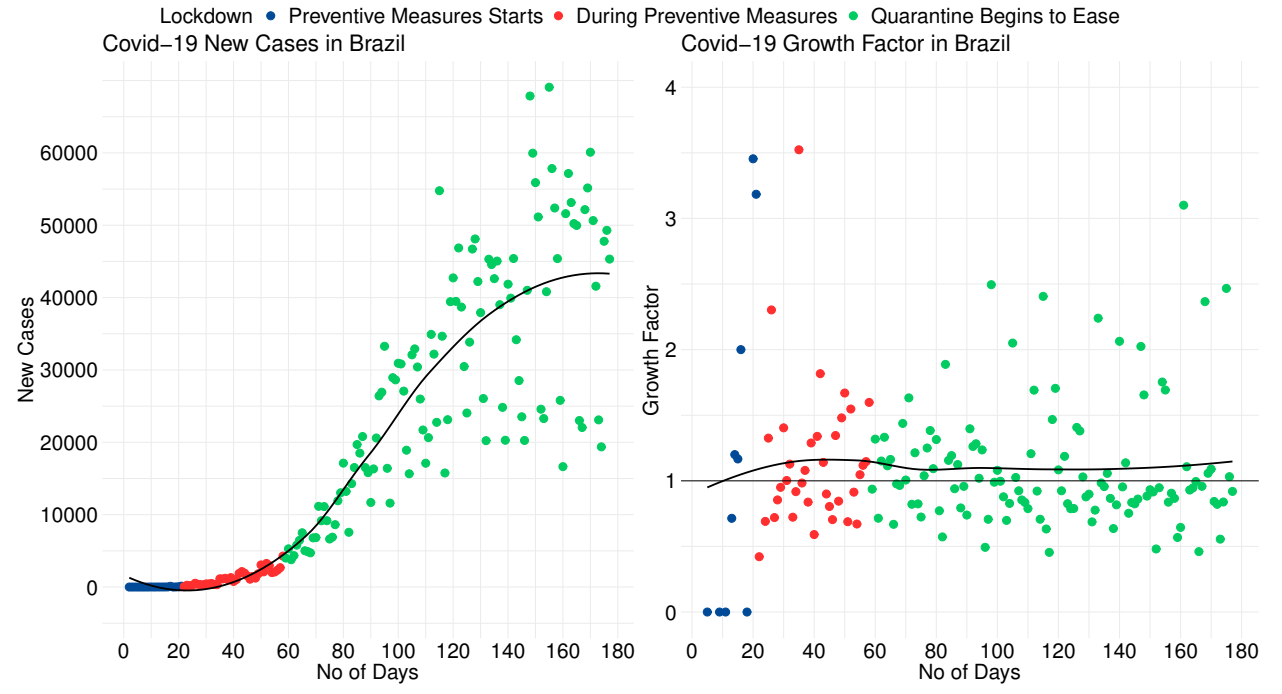

Figure 12: Lockdown assessment in Brazil. 


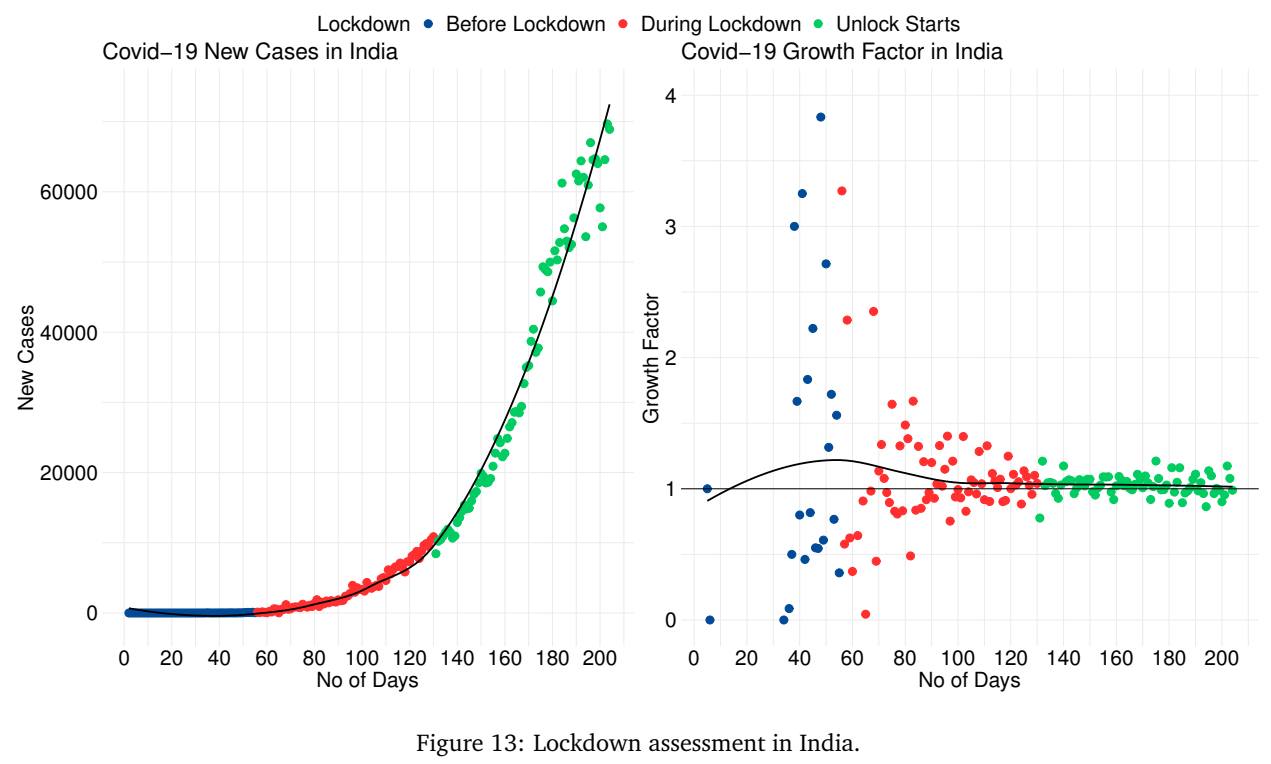

